\title{
Impact of Sectoral Operational Programme Human Resources Development (SOP HRD) on Doctoral Thesis Rate of Defending and Publishing Activity of Doctoral Students Enrolled in the Universities of Agricultural Sciences and Veterinary Medicine from Romania
}

\author{
Vasile Lucian NAȘ, Sebastian Călin VAC*, Sorina DÎRJAN, Alexandra Elena ANASTASIU \\ University of Agricultural Sciences and Veterinary Medicine from Cluj-Napoca, Romania, 3-5 Calea \\ Mănăștur, 400372 Cluj-Napoca, Romania \\ *corresponding author, e-mail: calin.vac@usamvcluj.ro
}

Bulletin UASVM series Agriculture 73(1) / 2016

Print ISSN 1843-5254, Electronic ISSN 1843-5394

DOI 10.15835/buasvmcn-agr: 12014

\begin{abstract}
In the last 15 years, from the point of view of enrollment, the evolution of higher education in the fields of agriculture and veterinary medicine emphasizes a continuous increase in the number of students. In this study we propose an analysis of the SOP HRD impact on the doctoral studies in the fields of agronomy and veterinary medicine, expressed in publishing activity, participations to conferences and rate of overall defended theses by four Universities of Agricultural Sciences and Veterinary Medicine from Romania. STATISTICA v. 8.0 for Windows, software was used for data processing. Strong interrelationships are emphasized $(\mathrm{R}=0.873,76.30 \%)$ between the defended doctoral theses, published papers and presented papers at conferences.. According to the Principal Component Analysis, the number of published papers has almost the same importance (52.10\%), although is slightly higher, compared to the number of presentations held at conferences (47.90\%). The Cluster Analysis and ANOVA Analysis of Variance show that published papers are the most important factor in defending doctoral theses considered in all 8 SOP HRD projects in the field of agronomy and veterinary medicine.
\end{abstract}

Keywords: Cluster Analysis, Multiple Regression, Principal Component Analysis, Variance Analysis

\section{INTRODUCTION}

In Romania, if we analyse the evolutional tendencies of the higher education, from the point of view of enrollment, there is a continuous increase in the number of students that may be noticed in the last 15 years, overall. The same tendency may also be reported in agricultural and veterinary medicine higher education.

According to official documents (National Strategic Reference Framework, 2007-2013), the high school graduates are opting for a continuation of their studies and prefer the higher education, due to a series of reasons. Among the premises that represent the basis of this preferences, one may mention:

The development of private higher education;

The creation of university networks by founding new universities or developing subsidiaries of the large traditional universities in locations with no tradition;

Increasing the degree of absorption, on the labor market, of people who benefit from superior education, which led to a reduced risk of unemployment for the higher education graduates.

In the meantime, we cannot neglect the issue concerning the access of the candidates from rural 
areas and other vulnerable groups the higher education. Currently, their share is reduced. We deem that the relatively high costs, which are involved in this type of education, represent the most important reason of this situation.

If we discuss the higher education participation in Romania, in terms of "Bologna" cycles, we note the biggest share of participation in bachelor programmes. Although the participation to master studies is situated on an increasing curve, mainly due to the requirements of the labor market, it is lower compared to number of graduates from higher education bachelor programmes.

The participation to doctoral programmes is characterized by fluctuations from one year to another. The Sectoral Operational Programme Human Resources Development (SOP HRD) brought one positive contribution to improvement of participation to doctoral studies in all fields of higher education, including the agronomic and veterinary medicine (SOP HRD 2007-2013, Annual Report of Implementation, 2008, 2009, 2010, 2011, 2012, 2013, 2014).

Taking into account the above mentioned aspects, in our study we propose an analysis of the SOP HRD impact on the doctoral ptogrammes in the fields of agronomy and veterinary medicine, expressed in publishing activity, participations to conferences and rate of overall defended theses by four Universities of Agricultural Sciences and Veterinary Medicine from Bucharest, Cluj-Napoca, Timisoara, and Iasi.

\section{MATERIAL AND METHOD}

Our research was developed within the Universities of Agricultural Sciences and Veterinary Medicine (UASVM) from Romania, which are located in Bucharest, Cluj-Napoca, Iasi and Timisoara.

All data collected from public reports available from 8 SOP HRD projects developed in UASVM Bucharest (projects no. 107/1.5/S/76888, and 88/1.5/S/52614), UASVM Cluj-Napoca (projects no. 6/1.5/S/20, and 88/1.5/S/49598),
UASVM Iasi (projects no. 6/1.5/S/7-ID4781, and $88 / 6 / 1.5 / S / 52176)$, and UASVM Timisoara (projects no. 6/1.5/S/21-ID6540, and 88/6/1.5/S/80127), as shown in Table 1 , were taken into account. The published papers, presentations at conferences, and the rate of defended theses were established as indicators emphasizing the impact of SOP HRD programmes upon the quality of $\mathrm{PhD}$ students' publishing activity during preparation of their doctoral theses and also the rate of defended theses.

The ANOVA analysis of variance and multivariate approach expressed by multiple correlations analysis together with Cluster Analysis (CA) and factorial analysis were implemented.

The Principal Component Analysis (PCA), as a factorial analysis tool, took into consideration two reference factors (number of published papers Factor 1, and number of conference presentations - Factor 2) in order to emphasize the distribution of the number of defended theses, and number of doctoral students (target group), function of these.

We used the Cluster Analysis in order to emphasize the interrelationship between the number of defended theses, number of published papers, and number of conference presentations , by their grouping in distinct clusters.

The reason of the implementation of the ANOVA analysis of variance is determined by our interest in classifying the defended theses, number of published papers, and number of conference presentations function of their importance within the process of elaboration of doctoral theses in the agronomic and veterinary medicine fields.

All data were processed with STATISTICA v. 8.0 for Windows, software.

\section{RESULTS AND DISCUSSIONS}

At first sight, one may notice that the number of presented papers and published papers taken into consideration within the present study exceed the proposed values, while a very high percent of defended theses is reported (98.99\%). In these conditions, a strong interdependence between

Tab. 1. The result indicators reported by 8 SOP HRD projects implemented in UASVMs from Romania

\begin{tabular}{cccccc}
\hline \multirow{2}{*}{$\begin{array}{c}\text { Universities } \\
\text { (no.) }\end{array}$} & $\begin{array}{c}\text { Projects } \\
\text { (no.) }\end{array}$ & Target & \multicolumn{3}{c}{$\%$ of fulfillment } \\
\cline { 4 - 6 } & 8 & group (no.) & Defended theses & Presented papers & Published papers \\
\hline 4 & 403 & 98.99 & 170.39 & 241.48 \\
\hline
\end{tabular}


defended theses, presented papers and published papers is reported. The value of the multiple correlation coefficient is $\mathrm{R}=0.873$, which explains $76.30 \%$ of the sample. The multiple correlation analysis applied to the result indicators generated by the 8 studied projects, reported by the UASVMs from Romania, emphasize an increase of the share of defended thesesup to $100 \%$, when the number of the presented papers is greater than 60 , and the number of published papers greater than 80 (Fig. 1).

The Principal Component Analysis (PCA) shows that the number of published papers (Factor 1) have almost the same importance $(52.10 \%)$ as the number of presentations given at conferences (Factor 2) that have a share of $47.90 \%$. The number of defended doctoral theses increases with the number of both presented and published papers, while the number of doctoral students presents a direct dependence of the number of published papers, and a lower interrelationship with the number of papers presented at scientific conferences (Fig. 2a).

The implementation of the Cluster Analysis (CA) in order to group the papers presented at conferences, the number of defended doctoral theses and the number of published papers function shows their importance and interrelationships established between the above mentioned result indicators. The number of published papers constitute a single cluster, while the number of papers presented to conferences and number of defended theses are part of the same cluster (Fig. 2b).

The ANOVA Analysis of Variance (Tab. 2) allows us to rank the analyzed result indicators available from the 8 SOP HRD projects developed in UASVMs from Romania.

Thus, the most important contribution to the development of the doctoral theses taken into consideration within above mentioned projects in the fields of agronomy and veterinary medicine are the published papers and presented papers (Tab. 2).

\section{CONCLUSION}

The result indicators reported by UASVMs from Romania, are in a strong interrelationship. This is emphasized by the value of the coefficient of multiple correlation of $\mathrm{R}=0.873$, which explains

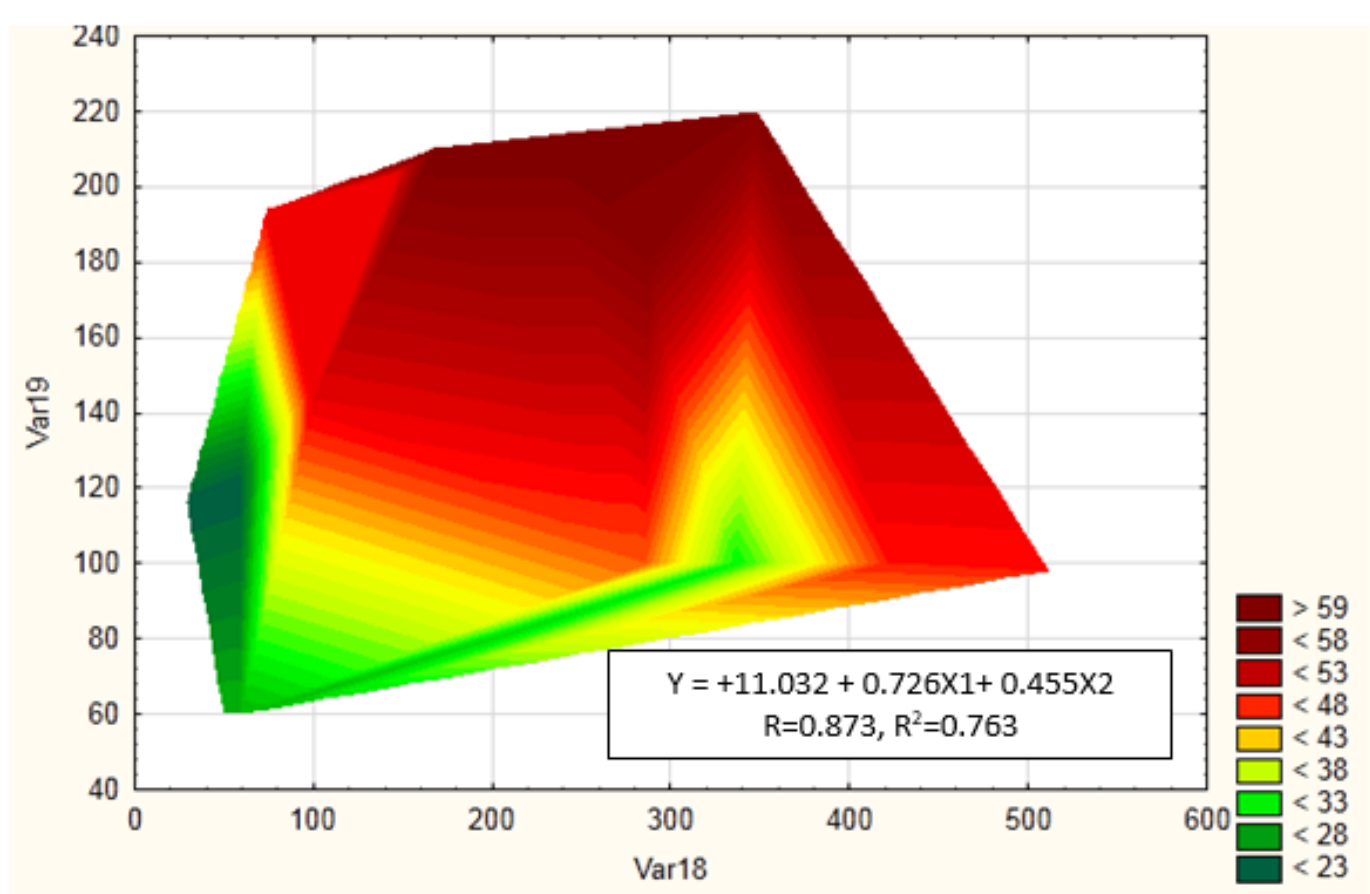

Note: Var 18, X1 - presented papers; Var 19, X2 - published papers.

Fig. 1. The interrelationship between presented papers, published papers and defended doctoral theses by the doctoral students from all analyzed Universities of Agricultural Sciences and Veterinary Medicine, during 2012-2014, within the 8 analyzed SOP HRD Projects. 


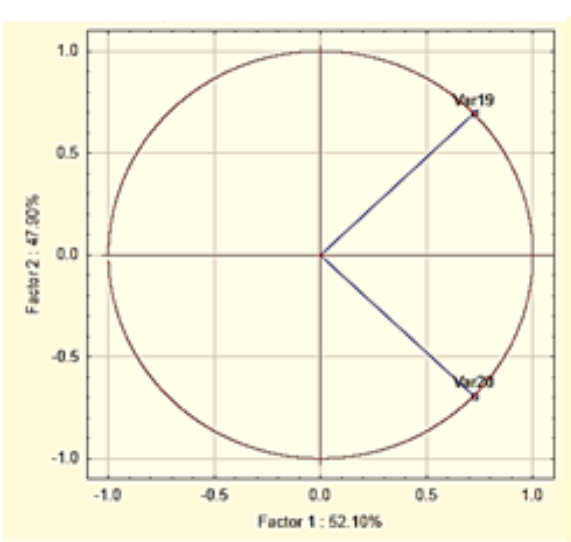

Note 1: Var 19 - defended doctoral theses; Xar 20 - number of doctoral students.

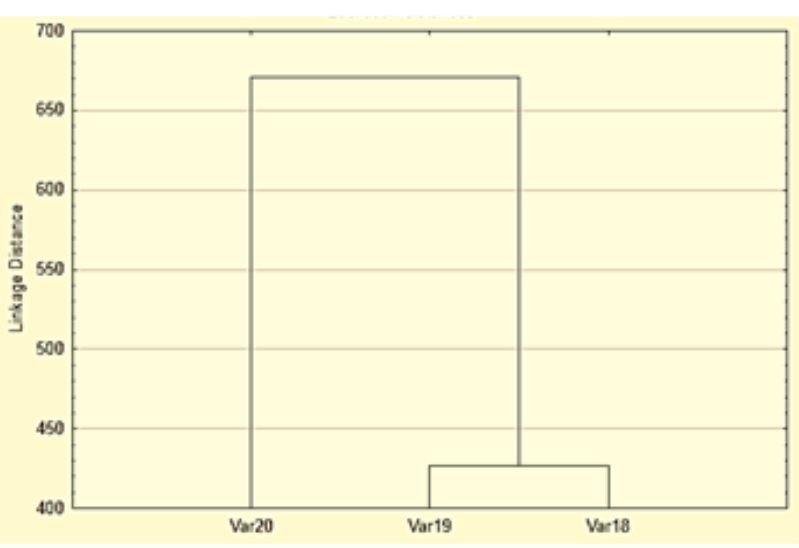

Note 2: Var 18 - defended doctoral theses; Var 19 - papers presented at conferences; Var 20 - published papers.

a.PCA

b.CA

Fig. 2. The PCA and CA applied to the result indicators of the SOP HRD projects analyzed from the Universities of Agricultural Sciences and Veterinary Medicine from Romania, during 2012-2014.

Tab. 2. The variance analysis (two-ways ANOVA) applied to the scientific activity of doctoral students from the Universities of Agricultural Sciences and Veterinary Medicine from Romania, who defended their doctoral theses during 2012-2014, within the SOP HRD Projects

\begin{tabular}{ccccc}
\hline Source of variation & $\begin{array}{c}\text { The sum of squares Degree of freedom } \\
\text { (SS) }\end{array}$ & $\begin{array}{c}\text { The mean } \\
\text { square (MS) }\end{array}$ & F \\
\hline Repetitions R & 0.61 & 2 & 0.33 & 1.19 \\
\hline A Factor - presented papers & $2,513.08$ & 3 & 228.46 & 116.88 \\
\hline Error - A & 132.67 & 1 & 33.17 & \\
\hline B Factor - published papers & $4,518.34$ & 3 & $3,012.20$ & 931.33 \\
\hline A x B & $8,254.20$ & 2 & $1,012.66$ & 851.98 \\
\hline Error - B & 0.08 & 1 & 0.11 & \\
\hline Total & 21,205 & 12 & &
\end{tabular}

a large part of the variation within the sample (76.30\%).

The Principal Component Analysis (PCA) emphasizes that the number of published papers have almost the same importance (52.10\%), although is slightly greater, compared to the number of conference presentations (47.90\%), within the process of defending the doctoral theses by a specific number of doctoral students, within SOP HRD projects developed by the UASVMs from Romania. The Cluster Analysis emphasizes a separate cluster composed of only one branch, which corresponds to the published papers. The same, ANOVA Analysis of Variance points out that published papers are the most important factor in defending the doctoral theses considered in all 8 SOP HRD projects in the field of agronomy and veterinary medicine.

Thus, our study not only emphasizes the importance of the publishing activity of the doctoral students, but also the positive impact of the implementations of the SOP HRD on doctoral programmes in the fields of agronomy and veterinary medicine, expressed by the high percent of elaborated doctoral theses (98.99\%), and stimulating effect upon the target group's publishing activity. 


\section{REFERENCES}

1. *** (2007). Romanian Government, Ministry of Labor Family and equality of Chances, National Strategic Reference Framework, 2007-2013.

2. *** (2008). Romanian Government, Ministry of Labor Family and equality of Chances, SOP HRD 2007-2013, Annual Report of Implementation [In Romanian].

3. *** (2009). Romanian Government, Ministry of Labor, Family and equality of Chances, SOP HRD 2007-2013, Annual Report of Implementation [In Romanian].

4. *** (2010). Romanian Government, Ministry of Labor, Family and equality of Chances, SOP HRD 2007-2013, Annual Report of Implementation [In Romanian].
5. *** (2011). Romanian Government, Ministry of Labor, Family and equality of Chances, SOP HRD 2007-2013, Annual Report of Implementation [In Romanian].

6. *** (2012). Romanian Government, Ministry of Labor, Family and equality of Chances, SOP HRD 2007-2013, Annual Report of Implementation [In Romanian].

7. *** (2013). Romanian Government, Ministry of Labor, Family and equality of Chances, SOP HRD 2007-2013, Annual Report of Implementation [In Romanian].

8. *** (2014). Romanian Government, Ministry of Labor, Family and equality of Chances, SOP HRD 2007-2013, Annual Report of Implementation [In Romanian]. 